\title{
Attitudinal dimensions of food choice and nutrient intake
}

\author{
BY MARGO E. BARKER ${ }^{1}$, KATE A. THOMPSON ${ }^{2}$ AND SALLY I. MCCLEAN ${ }^{3}$ \\ ${ }^{1}$ Centre for Human Nutrition, University of Sheffield, Northern General Hospital, Herries Road, \\ Sheffield S5 $7 \mathrm{AU}$ \\ ${ }^{2}$ Centre for Health and Social Research and ${ }^{3}$ Department of Mathematics, University of Ulster, \\ Coleraine BT52 ISA
}

(Received 7 June 1994 - Revised 10 February 1995 - Accepted 13 March 1995)

\begin{abstract}
A diet low in fat and rich in fibre has been recommended to optimize general health and in particular cardiovascular health. Health attitudes to fat and fibre were studied in relation to food and nutrient intake and sociocultural and lifestyle factors amongst the general population of Northern Ireland. The study population comprised 592 adults aged 16-64 years; health attitudes to fat and fibre were assessed by questionnaire (based on a social psychological model, which adjusted for taste and convenience factors). Dietary intake was estimated using the weighed inventory technique. Fat-phobic and fibre-philic attitudes were more prevalent in women than men. Fat-phobic attitudes in women were inversely related to intake of fat through a reduced intake of chips, butter and sausages. In contrast, men's fat-phobic attitudes were not strongly correlated with fat intake; consumption of chips and sausages was negatively associated with fat-phobic attitudes, but cake/biscuit, buns/pastries and milk consumption was positively associated with fat-phobic attitudes. Fibre-philic attitudes were positively associated with dietary fibre intake; intakes of potatoes, vegetables, wholemeal bread and breakfast cereal were positively associated with fibre-philic attitudes. There were clear sociocultural and lifestyle differences in relation to dietary attitude. These findings have implications for campaigns designed to effect population dietary change.
\end{abstract}

Dietary survey: Health attitudes

Contemporary nutrition education has tended to emphasize the health-threatening aspects of fat, and the health-promoting aspects of dietary fibre. Particular emphasis has been placed on the relationship between fat and fibre intake and cardiovascular health. However, sensory and cultural factors such as taste, enjoyment and convenience also impinge on food choice and may either attenuate or augment nutritional reasons for choosing particular foods.

An understanding of the impact of these factors on food choice and nutrient intake is important given the priority for population dietary change (Department of Health, 1992). A number of studies (Shepherd \& Stockley, 1985, 1987; Towler \& Shepherd, 1992; Lloyd et al. 1993) have applied theoretical models, specifically the theory of reasoned action (Fishbein \& Ajzen, 1975), to quantify the interaction between nutritional motives for food choice and nutrient intake. However, these studies have been limited by the precision of the dietary assessment; food-frequency questionnaire methods have been widely used and dietary classification has been into broad heterogeneous food groups. The study of the diets of a large, representative sample of the Northern Irish population using the weighed inventory technique (Barker et al. 1989) allowed the opportunity to explore the relationship between dietary attitudes and food and nutrient intake. The components of taste and convenience were intrinsic to the attitude model used, thus the relationship between a composite dietary attitude and food and nutrient intake was explored.

Information on dietary attitudes was collected as part of a cross-sectional population 
study of diet, lifestyle and health in Northern Ireland (Barker et al. 1989). The health attitude inventory (HAI; Gallacher \& Bennett, 1990) was designed to measure quantitatively a range of attitudes which may impact on lifestyle and health. The underlying rationale of the instrument is the social psychological model of Fishbein \& Ajzen (1975) in which behaviour is construed as a function of attitudes, which are in turn a product of beliefs and values. The HAI measures beliefs and values towards smoking, exercise, type-A behaviour and fat- and fibre-rich food, specifically fried food and dairy products, and vegetables and wholemeal bread respectively. For the purposes of the present investigation dietary attitudes only are considered.

In the HAI there are a number of distinct attitude components of diet; they are taste, convenience, general health, fat content, digestion and cardiovascular risk. Each attitude component is measured as the product of beliefs about the outcomes of behaviour and the values associated with the behaviour. In addition, the HAI assesses the perceived social pressure to behave, which in the psychological model may be combined with the individual attitudinal components to predict intention to behave. However, previous attitudinal studies of diet (Shepherd \& Stockley, 1985; Tuorila, 1987) have shown that the subject's own attitude far outweighs perceived social pressure as a determinant of consumption. Hence, in the present study we investigated specifically the relationship between the subjects' own attitudes (estimated as the sum of belief-values) and nutrient intake and consumption of specific foods. The investigation also explored how dietary attitudes coexist with sociodemographic and lifestyle variables.

\section{METHODOLOGY}

Detailed descriptions of the sampling methods, study instruments and protocols for data collection are provided by Barker et al. (1989). Briefly, the sampling method was a two-tier process, first of Northern Irish households and second of individuals within the sampled households. Initially, a total of 1180 households were randomly selected from the Household Valuation List (Policy Planning and Research Unit, Belfast). All households were sent an introductory letter explaining the nature of the study, and explaining that a fieldworker would call to visit them. Of the 1180 addresses, 383 were ineligible for the study as they were unoccupied, inhabited by people over the age of 65 years, demolished properties, or commercial premises. Thus, 797 addresses were designated 'effective'. The second stage sampling involved randomly selecting an individual from each household. This was done using the Kish (1965) method, which is designed to produce a sample reflecting the age and sex distribution of the population from which the sample is drawn.

All eligible subjects ( $n$ 797) were asked to complete a $7 \mathrm{~d}$ weighed inventory of all food and drink consumed. Initially 670 subjects agreed to cooperate. Subjects, closely supervised by fieldwork assistants, weighed (Miniscale, PC International, Little Abington, Cambs.) and recorded all food consumed within the home; plate waste was also recorded. For food consumed outside the home, estimated weights were used in conjunction with descriptive information. Of the 670 subjects who agreed to cooperate, 592 ( $74 \%$ of the eligible sample) satisfactorily completed the weighed record.

From the weighed record, mean daily nutrient intakes were calculated for fat and dietary fibre using a computerized nutrient database based on McCance and Widdowson's The Composition of Foods (4th ed.; Paul \& Southgate, 1978) with supplementary analyses (Wiles et al. 1980). Mean daily intakes of individual foods and food groups were also calculated using dietary software.

Personal, social and lifestyle information was collected by interviewer-administered questionnaire. The socio-economic profile of the sample was ascertained by reference to the 
current occupation of the head of the household using the Registrar General's classification (Office of Population Censuses and Surveys, 1980); subsequent classification comprised the categories of 'non-manual', 'manual', 'unemployed' and 'other' (unclassified subjects). Height and weight measurements were made using a folding stadiometer and Soehnle digital electronic scales respectively. Both instruments were obtained from CMS Weighing Ltd., London. BMI was calculated using the Quételet index : weight $(\mathrm{kg}) /$ height $\left(\mathrm{m}^{2}\right)$.

The HAI was left with the subject on the fifth day of dietary recording and was collected at the end of the study week. The HAI is a seventy-six item questionnaire; not all subjects fully completed the questionnaire. The relevant fat and fibre belief and value items were completed by 509 and 536 subjects respectively. Twenty-five male and fifty-four female subjects failed to complete the fat belief section of the HAI questionnaire. Their mean BMI was not significantly (independent $t$ tests) different from those of the men and women who completed the questionnaire. These results suggest that failure to complete the fat beliefs section was not due to relative weight. The respective mean BMI $\left(\mathrm{kg} / \mathrm{m}^{2}\right)$ figures for men and women were: 24.78 and 24.54 for compilers and 24.47 and 24.93 for non-compliers.

The HAI (see Appendix 1) assesses attitudes to fat and fibre through measuring beliefs and values about dairy produce and fried food and wholemeal bread and vegetables respectively. Beliefs were scored on a monotonically increasing scale from one to four to reflect increasing certainty of belief; these scores were rescaled to the range nought to three. Values were scored one to five and then rescaled to give a range from minus two to plus two. Each belief score was then multiplied by the appropriate value score to form an attitude score. These were then summed for the five components of fat attitude (taste, convenience, fat content, general health and cardiovascular health) with taste and convenience being given negative weightings. Thus, an overall attitude score for fat was calculated, a higher score reflecting an increased perception of fat as health threatening. A similar overall score was calculated for the four attitude components of fibre (taste, dietary balance, general health and cardiovascular risk), a higher score reflecting increased perception of fibre as health promoting. In this case the attitudinal component of taste was given a positive weighting.

Statistical analysis was carried out using Pearson correlation coefficients to test the association between attitudes and food and nutrient intake. Attitude scores and nutrient intakes followed a normal distribution. Food intake distributions tended to be skewed, often following a bimodal distribution due to a proportion of the population consuming zero quantities in the survey week. Analysis of covariance, where all the terms are included in a single model, was used to examine the relationship between attitude scores for fat and fibre and socio-economic group, marital status, religion, geographical location (urban/rural), household size and smoking and drinking behaviour; BMI and age were covariates in the analysis. The definition of each factor used in the analysis of covariance is shown in Table 1. The SPSS statistical package was used to conduct all analyses.

\section{RESULTS}

The overall attitude scores for fat and fibre are shown in Table 2 in relation to the sex of the subject. It is clear that women tended to have greater attitude scores than men; in the case of fibre the sex difference attained statistical significance $(P<0.001)$.

Table 3 shows the correlation between fat attitudes, mean daily fat intake and intake of various fat-containing foods. In men there was no significant correlation between attitudes to fat and fat intake. In contrast, women's attitude to fat was significantly $(P<0.01)$ inversely related to fat intake. In relation to actual food consumption there were significant inverse correlations between fat attitude score and chips and sausage consumption in men. 
Table 1. Definitions of factors used in the analysis of covariance of fat and fibre

\begin{tabular}{ll}
\hline \hline Factor & Definition \\
\hline Socio-economic group & Non-manual; manual; unemployed; other \\
Marital status & Married; widowed, divorced and separated; single \\
Religion & Protestant; Catholic; other \\
Geographical location & Urban; rural \\
Smoking behaviour & Smoker; non-smoker \\
Drinking behaviour & $>$ once a week; once a week; < once a week \\
Household size & $1 ; 2 ; 3 ; 4$ or more persons \\
\hline \hline
\end{tabular}

Table 2. Attitude scores by sex for fat and fibre amongst Northern Irish subjects (Mean values with their standard deviations)

\begin{tabular}{|c|c|c|c|c|c|}
\hline & \multicolumn{4}{|c|}{ Attitude score } & \multirow{3}{*}{$\begin{array}{c}\text { Significance } \\
\text { level }\end{array}$} \\
\hline & \multicolumn{2}{|c|}{ Men } & \multicolumn{2}{|c|}{ Women } & \\
\hline & Mean & SD & Mean & SD & \\
\hline Fat & $4 \cdot 1$ & $13 \cdot 3$ & $6 \cdot 2$ & $12 \cdot 9$ & NS \\
\hline & \multicolumn{2}{|c|}{$(n 232)$} & \multicolumn{2}{|c|}{$(n 277)$} & \\
\hline Fibre & \multicolumn{2}{|c|}{$(n 242)$} & $35 \cdot 4$ & $14 \cdot 9$ & $P<0.001$ \\
\hline
\end{tabular}

Table 3. Correlation between fat attitude score and mean daily fat intake $(g / d)$ and mean daily consumption $(\mathrm{g} / \mathrm{d})$ of various foods by Northern Irish subjects

\begin{tabular}{|c|c|c|c|c|}
\hline Intake & $\begin{array}{c}\text { Pearson } \\
\text { correlation } \\
\text { coefficient } \\
\text { Men } \\
(n 232)\end{array}$ & $\begin{array}{l}\text { Significance } \\
\text { level }\end{array}$ & $\begin{array}{l}\text { Pearson } \\
\text { correlation } \\
\text { coefficient } \\
\text { Women } \\
(n 277)\end{array}$ & $\begin{array}{c}\text { Significance } \\
\text { level }\end{array}$ \\
\hline Fat intake & -0.02 & NS & $-0 \cdot 14$ & $P<0.01$ \\
\hline Chips & -0.13 & $P<0.05$ & $-0 \cdot 12$ & $P<0.05$ \\
\hline Milk & $0 \cdot 13$ & $P<0.05$ & 0.07 & NS \\
\hline Cream & 0.04 & NS & 0.00 & NS \\
\hline Cheese & 0.06 & NS & 0.01 & NS \\
\hline Yoghurt & $0 \cdot 38$ & $P<0.001$ & 0.48 & $P<0.001$ \\
\hline Butter & -0.04 & NS & $-0 \cdot 22$ & $P<0.001$ \\
\hline Beef & -0.07 & NS & -0.01 & NS \\
\hline Poultry & -0.01 & NS & -0.03 & NS \\
\hline Sausages & $-0 \cdot 18$ & $P<0.01$ & -0.15 & $P<0.01$ \\
\hline Fish & -0.01 & NS & -0.03 & NS \\
\hline Cakes and biscuits & 0.19 & $P<0.01$ & 0.02 & NS \\
\hline Buns and pastries & 0.19 & $P<0.01$ & 0.03 & NS \\
\hline Breakfast cereals & $0 \cdot 15$ & $P<0.01$ & 0.09 & NS \\
\hline
\end{tabular}

Women's consumption values for chips, sausages and butter were significantly negatively associated with fat attitude score. In men there was a strong positive association between fat attitude score and yoghurt consumption $(P<0.001)$, as well as with cakes/biscuits and buns/pastry consumption $(P<0.01)$. Lesser positive correlations were observed between 
Table 4. Correlation between fibre attitudinal score and mean daily fibre intake $(\mathrm{g} / \mathrm{d})$ and mean daily consumption $(\mathrm{g} / \mathrm{d})$ of various foods by Northern Irish subjects

\begin{tabular}{lcccc}
\hline & $\begin{array}{c}\text { Pearson } \\
\text { correlation } \\
\text { coefficient } \\
\text { Men } \\
(n \text { 242) }\end{array}$ & $\begin{array}{c}\text { Significance } \\
\text { level }\end{array}$ & $\begin{array}{c}\text { Pearson } \\
\text { correlation } \\
\text { coefficient } \\
\text { Women } \\
(n \text { 294) }\end{array}$ & $\begin{array}{c}\text { Significance } \\
\text { level }\end{array}$ \\
Intake & 0.23 & $P<0.001$ & 0.29 & $P<0.001$ \\
Fibre intake & 0.39 & $P<0.001$ & 0.40 & $P<0.001$ \\
Potatoes & 0.26 & $P<0.001$ & 0.36 & $P<0.001$ \\
Vegetables & 0.29 & $P<0.001$ & 0.37 & $P<0.001$ \\
Wholemeal bread & 0.16 & $P<0.01$ & 0.28 & NS \\
Fruit & 0.20 & $P<0.01$ & 0.01 & \\
Breakfast cereal & & &
\end{tabular}

Table 5. Analysis of covariance of attitude towards fat amongst Northern Irish subjects*

\begin{tabular}{|c|c|c|}
\hline Covariates (regression coefficients) & Men ( $n$ 232) & Women (n 277) \\
\hline Age (years) & $0.063 \mathrm{NS}$ & $-0.007 \mathrm{NS}$ \\
\hline BMI $\left(\mathrm{kg} / \mathrm{m}^{2}\right)$ & $0.081 \mathrm{NS}$ & $0-138 \mathrm{NS}$ \\
\hline \multicolumn{3}{|c|}{ Factors (deviations from the grand mean) } \\
\hline Grand mean & $4 \cdot 21$ & 6.43 \\
\hline Socio-economic group & NS & NS \\
\hline Marital status & $P<0.05$ & NS \\
\hline Married & $1 \cdot 01$ & $-0 \cdot 02$ \\
\hline Widowed/Divorced/Separated & -7.98 & $-3 \cdot 50$ \\
\hline Single & -0.42 & 1.75 \\
\hline Religion & NS & NS \\
\hline Geographical location & NS & NS \\
\hline Smoking behaviour & NS & NS \\
\hline Drinking behaviour & NS & NS \\
\hline Household size & NS & NS \\
\hline
\end{tabular}

* Adjusted $R^{2} 0 \cdot 120$ and 0.074 for men and women respectively.

fat attitude score and milk $(P<0.05)$ and breakfast cereal $(P<0.01)$ consumption. In women, fat attitude score was significantly $(P<0.001)$ positively correlated with yoghurt consumption.

Table 4 shows the associations between fibre attitude score and mean daily intake of dietary fibre, potatoes, vegetables, fruit, wholemeal bread and breakfast cereals in men and women. All the correlations were positive and attained statistical significance, with the exception of breakfast cereal intake in women.

From the analysis of covariance of attitude to fat (Table 5) it is evident that fat attitudinal score was not related to age or BMI. The only sociodemographic factor to vary significantly $(P<0.05)$ was marital status in men; married men tended to have higher fat attitudinal scores than single, widowed, divorced or separated men. In contrast, single women had higher fat attitudinal scores than other groups, although the effect was not significant.

The analysis of covariance of attitude to fibre (Table 6) showed that age was positively $(P<0.01)$ related to fibre score in men and women. There was also a significant relationship with socio-economic group in women; women from non-manual and manual 
Table 6. Analysis of covariance of attitude towards fibre amongst Northern Irish subjects*

\begin{tabular}{lcc}
\hline \hline Covariates (regression coefficients) & Men $(n$ 242) & Women $(n$ 294) \\
\hline Age (years) & $0.222 P<0.01$ & $0.240 P<0.01$ \\
BMI (kg/m $\left.\mathrm{m}^{2}\right)$ & $0.299 \mathrm{NS}$ & $0.055 \mathrm{NS}$ \\
Factors (deviations from the grand mean) & & \\
Grand mean & 29.84 & 35.52 \\
Socio-economic group & NS & $P<0.05$ \\
Non-manual & 0.98 & 2.11 \\
Manual & $-1 \cdot 70$ & 0.69 \\
Unemployed & 1.01 & -7.81 \\
Other & $2 \cdot 02$ & -1.43 \\
Marital status & NS & NS \\
Religion & NS & NS \\
Geographical location & NS & $P<0.05$ \\
Smoking behaviour & NS & -1.67 \\
Smoker & -0.60 & 1.99 \\
Non-smoker & 0.86 & NS \\
Drinking behaviour & NS & NS \\
Household size & NS & \\
\hline \hline
\end{tabular}

* Adjusted $R^{2} 0.128$ and 0.135 for men and women respectively.

households had higher scores than women from unemployed and other (economically inactive) households. Smoking habit was also associated with the fibre attitudinal score in women; non-smokers tended to have higher scores.

\section{DISCUSSION}

The recent work of Lloyd et al. (1993) focused on attitudes to low-fat diets and the relationship with nutrient intake in a group of British consumers; it was demonstrated that subjects consuming high-fat diets had similar attitudes to dietary change compared with those consuming low-fat diets. The findings of the current study show this effect in men but not in women. A sex difference in dietary attitude is well documented (Blaxter, 1990; Towler \& Shepherd, 1992; Barker \& Thompson, 1993); women are generally more aware of diet and health issues and endorse dietary change to a greater degree than men. In the current study, as the mean attitude scores and variances show, women perceived fat as more health-threatening and fibre as more health-promoting than did men. In addition, it is evident that fat-phobic attitudes of women and men manifest themselves in different ways when it comes to food choice.

In men, although attitude and fat intake are not related, men holding negative attitudes to fat consume lesser quantities of sausages and chips, but not beef, butter, cream or cheese. At the same time, negative attitudes to fat are associated with increased consumption of milk, yoghurt, cakes/biscuits and buns/pastries. These apparently paradoxical effects may be a result of misunderstanding as to the fat content of foods, as well as to the relative position particular foods hold within the dominant food ideology. Clearly, certain foods such as chips and sausages, which have a low position in the food hierarchy (Charles $\&$ Kerr, 1988), have been imbued with health-threatening connotations and are thus eschewed. In contrast, foods such as beef, cream and butter are valued and consumed in spite of their fat content. The value men attach to the consumption of meat, especially red meat, has been highlighted by Charles \& Kerr (1988). The greater consumption of cakes and biscuits by fat-phobic men may be a combination of the high status cake has in the food hierarchy (Charles \& Kerr, 1988) and a misguided notion that cakes and biscuits are not 
a major source of fat. The greater consumption of yoghurt by men with fat-phobic views is congruent with yoghurt's image as a 'health' food. The effects observed for milk consumption are difficult to explain; we are unable to differentiate between reduced-fat milk and whole milk, which carry very different health connotations.

Thus, fat-phobic attitudes in men seem to be realized in avoidance of certain foods and a predilection for others. These attitudes, which are weighted for taste and convenience values, do not translate into a reduced fat intake. In contrast, women's fat-phobic attitudes translate into a reduced intake of fat, through reduced consumption of chips, butter and sausages. Unlike men, fat-phobic women do not consume greater quantities of fat-rich cakes/biscuits and buns/pastries. However, beef and cream follow the same pattern of consumption in relation to attitude as in men; they appear to be valued for their prestigious nature being at the apex of the food hierarchy.

It is, thus, apparent that fat-phobic attitudes affect food choice but are not always dominant. The juxtaposition of fat-phobic attitudes with a predilection for certain fat-rich foods demonstrates that attitude change needs to be combined with a knowledge of food values to be effective. This finding has implications for nutrition education programmes, and would indicate that to achieve population fat intake targets (Department of Health, 1992) nutrition education needs to be focused and food-based.

The effects for fibre are more straightforward; a fibre-philic attitude is associated with a greater intake of dietary fibre through increased intake of potatoes, vegetables, wholemeal bread and fruit. These effects are consistent for men and women. The only food that shows differences with sex is breakfast cereal (men with fibre-philic attitudes consume more). It would seem that the nutrition messages to consume more fibre have been effective; there is a clear understanding of the main food sources and there does not appear to be the same ambivalence towards fibre-rich foods as was apparent with fat-rich foods.

The interactions between attitude and sociodemographic variables are interesting. Unlike the study of Towler \& Shepherd (1992), which found that older subjects tended to have more positive views of fat, age was not associated with fat attitude in men or women. This was confirmed by tabulating fat scores by age group. Mean fat score was highest in the 30-39 years age group and lowest in the 16-29 years age group in men, while for women the 50-64 years age group had the highest score and the $40-49$ years age group the lowest. However, these age differences were not found to be statistically significant using ANOVA. In contrast, older people had more positive attitudes to fibre than did younger people. This effect is at odds with general attitudes towards diet in Northern Ireland; Barker \& Thompson (1993) reported that young people were more positive about dietary change and were more likely to have changed their diet compared with their older counterparts. We are unaware of any studies that have focused specifically on the relationship between age and attitudes towards fibre, so we are unable to evaluate this finding in the light of other evidence.

The lack of relationship between BMI and attitude to fat and fibre is discouraging, given the commitment by government to reduce levels of obesity (Department of Health, 1992). It would seem that attitudes are not influenced by body weight, but it should be noted that the components of taste and convenience are intrinsic to the attitude model. Overweight individuals may have strong perceptions of fat as health-threatening and fibre as healthpromoting; however, these perceptions may be outweighed by their score for taste and convenience. Further investigation into the interaction between components of attitude score and body weight would be enlightening.

Socio-economic group has been shown to have a major influence on dietary attitudes; many studies have demonstrated striking differences in attitude between the non-manual and manual social classes (Blaxter, 1990; Towler \& Shepherd, 1992; Barker \& Thompson, 
1993; Lloyd et al. 1993). Greater awareness of diet and health issues and more negative attitudes towards the consumption of fat are associated with social privilege. Social differences were observed in the current study for attitude to fibre but not to fat. Towler \& Shepherd (1992) reported that higher social class subjects had more negative views of fatcontaining foods (meat, meat products, dairy products and fried foods), although as a group they reported greater consumption of dairy products. It would appear that perceptions of fat as a health hazard do not automatically translate into effective dietary change. Certain foods, for example cream, butter and red meat are desired regardless. These effects may be due to their high ranking in the food hierarchy and their associated nutritional benefits; specifically, dairy products have been extolled for their Ca content.

Marital status was an important determinant of fat attitude in men; married men were much more likely to be fat-phobic than any other group. Dietary patterns are known to vary with marital status (Barker et al. 1990). The traditional role of women as servers and providers of food seems to be bound to issues of diet and health. Indeed, Charles \& Kerr (1988) noted that women take up the mantle of family health and that issues of health, food and nutrition are an important aspect of their role as wives and mothers.

Attitudes to fibre were associated with smoking habit in women but not in men. Nonsmoking women were more likely to consider fibre as health-promoting than their smoking counterparts. Blaxter (1990) showed that there were distinct lifestyle patterns. For example, regular drinking in women was associated with a good diet and smokers tended to have a poorer diet. The relationship between smoking and diet has been demonstrated in a number of studies (Thompson et al. 1992), and indeed in the present dataset (Strain et al. 1991) fibre intakes were greater in non-smokers compared with smokers. This effect may in part reflect attitudinal differences to fibre between smokers and non-smokers. Although in men the attitudinal difference between smokers and non-smokers did not reach statistical significance, the difference was in the same direction as for women. These differences probably reflect an overall difference in awareness and acceptance of health education issues between smokers and non-smokers. Again the sex difference substantiates the general differences in health attitudes between men and women.

In conclusion, the nurturing of fat-phobic attitudes in order to reduce fat intakes appears to be more effective in women than in men. However, some of the foods favoured by men and women with perceptions of fat as health-threatening are at odds with their attitudes. This may be due to a lack of knowledge about the fat content of food, the position certain foods hold within the food hierarchy and a general reticence to embrace dietary change. There may well be a necessity for invervention strategies which highlight such foods and increase public awareness of their fat content. Our findings suggest that the group most likely to benefit from such interventions are men who are unmarried. Nutrition messages about the benefits of a high-fibre diet appear to have been better understood than those for fat. However, there are still social and lifestyle barriers to dietary change.

The authors wish to acknowledge the financial support of the Health Promotion Trust. 


\section{APPENDIX 1 \\ The Northern Ireland Diet and Health Study Health Attitude Questionnaire}

Serial Number

Interviewer Number

District

Ward

Date

This questionnaire concerns your views on how various things affect you personally. Read each question carefully and show your answer circling the number which best reflects your view. Please answer all the questions as best you can and work quickly by giving the first answer that comes to you.

Example: Do you like playing golf?

Will exercise improve your own health and fitness?

Do you generally enjoy exercise?

Is it difficult to find time to exercise?

Will exercise help you lose weight?

Will exercise reduce your risk of a heart attack?

Do you generally enjoy the taste of dairy produce?

Will eating dairy produce improve your health?

Is dairy produce generally convenient to eat?

Does dairy produce contain a lot of fat?

Will eating dairy produce increase your risk of a heart attack?

Do you generally enjoy the taste of most vegetables?

Will eating vegetables improve your health?

Will eating vegetables give you a better balanced diet?

Will eating vegetables reduce your risk of a heart attack?

Do you generally enjoy the taste of fried food?

Will eating fried food harm your health?

Is frying generally a convenient way to cook?

Does fried food contain a lot of fat?

Will eating fried food increase your risk of a heart

Definitely

no

1

1

1

1

1

1

1

1

attack?

Do you generally enjoy the taste of wholemeal bread?

Will eating wholemeal bread improve your health?

Will eating wholemeal bread improve your digestion?

Will eating wholemeal bread reduce your risk of a

heart attack?

Will smoking harm your own health?

Is smoking generally unpleasant to others?

Do you generally enjoy smoking?

Is smoking expensive?

Will smoking increase your risk of a heart attack?

Will setting deadlines help you get things done?

Will getting angry help you get things done?

Will being competitive help you get things done?

Will working hard to meet deadlines increase your risk of a heart attack?

Will getting worked up and angry increase your risk of a heart attack?

Will being very competitive increase your risk of a heart attack?

Does your wife or closest friend like you to take exercise?

Probably
no
2
2
2
2
2
2
2
2
2
2
2

$\begin{array}{cc}\begin{array}{c}\text { Probably } \\ \text { yes }\end{array} & \begin{array}{c}\text { Definitely } \\ \text { yes }\end{array}\end{array}$

4

4

4

4

4

4

4

4

4

4

4

4

4

4

4

4

4

4

4

4

4

4

4

4

4

4

4

4

4

4

4

4

4

4

4

4 
Does your wife or closest friend like you to smoke?

Does your wife or closest friend like you to eat

wholemeal bread?

Does your wife or closest friend like you to eat vegetables?

Does your wife or closest friend like you to eat dairy produce?

Does your wife or closest friend like you to eat fried food?

Does your wife or closest friend like you to get things done quickly?

$\begin{array}{llll}1 & 2 & 3 & 4 \\ 1 & 2 & 3 & 4 \\ 1 & 2 & 3 & 4 \\ 1 & 2 & 3 & 4 \\ 1 & 2 & 3 & 4 \\ 1 & 2 & 3 & 4\end{array}$

How much do you like or distike each of the following?

Getting your enjoyment through smoking

Spending money on smoking

Unpleasantness to others caused by smoking

The taste of dairy produce in general

The convenience of eating dairy produce

The amount of fat in dairy produce

The taste of vegetables in general

Eating vegetables to improve the balance of your diet

The taste of fried food in general

The convenience of fried food

The amount of fat in fried food

The taste of wholemeal bread

Eating wholemeal bread to improve your

digestion

Getting your enjoyment through exercise

Putting time aside for exercise

Exercising to lose weight

Setting deadlines to get things done

Getting angry to get things done

Being competitive to get things done

$\begin{array}{ccc}\begin{array}{c}\text { Dislike } \\ \text { very } \\ \text { much }\end{array} & \begin{array}{c}\text { Dislike } \\ 1\end{array} & \begin{array}{c}\text { Not } \\ \text { sure }\end{array} \\ 1 & 2 & 3 \\ 1 & 2 & 3 \\ 1 & 2 & 3 \\ 1 & 2 & 3 \\ 1 & 2 & 3 \\ 1 & 2 & 3 \\ 1 & 2 & 3 \\ & & \\ 1 & 2 & 3 \\ 1 & 2 & 3 \\ 1 & 2 & 3 \\ 1 & 2 & 3 \\ 1 & 2 & 3 \\ & & \\ 1 & 2 & 3 \\ 1 & 2 & 3 \\ 1 & 2 & 3 \\ 1 & 2 & 3 \\ 1 & 2 & 3 \\ 1 & 2 & 3\end{array}$

Like
very
much
5
5
5
5
5
5
5
5

5
5
5
5
5
5
5
5
5
5
5

How much do you value each of the following?

Improving your health and fitness through exercise Improving your health by eating vegetables Improving your health by eating dairy produce Improving your health by eating wholemeal bread Reducing your risk of a heart attack by eating vegetables Reducing your risk of a heart attack through exercise Reducing your risk of a heart attack by eating wholemeal

Not at all
1
1
1
1
1
1
1

A littl Very much bread

How much do you fear each of the following?

Harming your health through smoking

Harming your health by eating fried food

Increasing your risk of a heart attack through smoking

Increasing your risk of a heart attack by eating fried

food

Increasing your risk of a heart attack by eating dairy produce

Increasing your risk of a heart attack by working hard to meet deadlines

$\begin{array}{ccc}\text { Not at all } & \text { A little } & \text { Moderately } \\ 1 & 2 & 3 \\ 1 & 2 & 3 \\ 1 & 2 & 3 \\ 1 & 2 & 3 \\ 1 & 2 & 3 \\ 1 & 2 & 3\end{array}$

Very

much

4

4

4

4 
Increasing your risk of a heart attack by getting worked up and angry

Increasing your risk of a heart attack by being very competitive

How much do you generally like to do what your wife or closest friend says

\begin{tabular}{|c|c|c|c|c|}
\hline 1 & & & 3 & 4 \\
\hline 1 & & & 3 & 4 \\
\hline $\begin{array}{l}\text { Couldn't } \\
\text { care } \\
\text { less } \\
1\end{array}$ & $\begin{array}{l}\text { Not } \\
\text { much } \\
2\end{array}$ & $\begin{array}{c}\text { Not } \\
\text { sure } \\
3\end{array}$ & $\begin{array}{c}\text { Like } \\
\text { to } \\
4\end{array}$ & $\begin{array}{c}\text { Like to } \\
\text { very } \\
\text { much } \\
5\end{array}$ \\
\hline
\end{tabular}

Thank you very much

\section{REFERENCES}

Barker, M. E., McClean, S. I., McKenna, P. G., Reid, N. G., Strain, J. J., Thompson, K. A., Williamson, A. P. \& Wright, M. E. (1989). Diet, Lifestyle and Health in Northern Ireland. A Report to the Health Promotion Trust. Coleraine: University of Ulster.

Barker, M. E. McClean, S. I., Thompson, K. A. \& Reid, N. G. (1990). Dietary behaviours and sociocultural demographics in Northern Ireland. British Journal of Nutrition 64, 319-329.

Barker, M. E. \& Thompson, K. A. (1993). Nutrition and health in Northern Ireland. In Social Attitudes in Northern Ireland: The Third Report, pp. 78-101 [P. Stringer and G. Robinson, editors]. Belfast: Blackstaff Press.

Blaxter, M. (1990). Health and Lifestyles. London: Tavistock/Routledge.

Charles, N. \& Kerr, M. (1988). Women, Food and Families. Manchester and New York: Manchester University Press.

Department of Health (1992). The Health of the Nation. A Strategy for Health in England. London: H. M Stationery Office.

Fishbein, M. \& Ajzen, I. (1975). Belief, Attitude, Intention and Behaviour: An Introduction to the Theory of Reasoned Action. Reading, MA: Addison-Wesley.

Gallacher, J. \& Bennett, G. (1990). Relations of attitudes to coronary risk behaviour in middle aged men. In Proceedings of the Second Conference of the Health Psychology Section of the British Psychological Society, Birmingham 1988, pp. 70-74. Leicester: British Psychological Society.

Kish, L. (1965). Survey Sampling. New York: Wiley.

Lloyd, H., Paisley, C. \& Mela, D. J. (1993). Changing to a reduced fat diet: attitudes and beliefs of UK consumers. European Journal of Clinical Nutrition 47, 361-373.

Office of Population Censuses and Surveys (1980). Classification of Occupations. London: H. M. Stationery Office.

Paul, A. A. \& Southgate, D. A. T. (1978). McCance and Widdowson's The Composition of Foods, 4th ed. London: H. M. Stationery Office.

Shepherd, R. \& Stockley, L. (1985). Fat consumption and attitudes towards food with a high fat content. Human Nutrition: Applied Nutrition 39A, 431-442.

Shepherd, R. \& Stockley, L. (1987). Nutrition knowledge, attitudes and fat consumption. Journal of the American Dietetic Association 87, 615-619.

Strain, J. J., Thompson, K. A. \& Barker, M. E. (1991). Dietary intakes of smokers and non-smokers in the Northern Ireland population. Proceedings of the Nutrition Society 51, $101 \mathrm{~A}$.

Thompson, R. L., Margetts, B. M., Wood, D. A. \& Jackson, A. A. (1992). Cigarette smoking and food and nutrient intakes in relation to coronary heart disease. Nutrition Research Reviews 5, 131-152.

Towler, G. \& Shepherd, R. (1992). Application of Fishbein and Ajzen's expectancy model to understanding fat intake. Appetite 18, 15-27.

Tuorila, H. (1987). Selection of milks with varying fat contents and related overall liking, attitudes, norms and intentions. Appetite 8, 1-14.

Wiles, S. J., Nettleton, P. A., Black, A. E. \& Paul, A. A. (1980). The nutrient composition of some cooked dishes eaten in Britain: a supplementary food composition table. Journal of Human Nutrition 34, 189-224. 